Planejamento estratégico situacional em saúde: abordagem da saúde do trabalhador na Estratégia Saúde da Família

\title{
Situational strategic planning in health and the approaches to worker's health in Family Health Strategy
}

\author{
Planeamiento estratégico situacional en salud: abordaje de la salud del trabajador en la \\ Estrategia Salud de la Familia
}

Recebido: $19 / 12 / 2019$
Aprovado: $31 / 03 / 2019$
Publicado: $15 / 05 / 2020$
Fernanda Carolina Camargo ${ }^{1}$

Gabriela Gonçalves Machado ${ }^{2}$ Luana Rodrigues Rosseto Felipe ${ }^{4}$ Gabriela Souza Faria ${ }^{4}$ Ana Laura Nogueira ${ }^{5}$ Sandra Cristina Romano Marquez Reis ${ }^{6}$ Isabel Aparecida Porcatti de Walsh ${ }^{7}$

Estudo por métodos mistos e de abordagem construcionista social, com objetivo de analisar a condução do Planejamento Estratégico Situacional em saúde para levantamento das demandas relacionadas à saúde do trabalhador com duas equipes da Estratégia Saúde da Família, realizado de maio a junho de 2018. Realizou-se observação ativa do território, entrevista com informantes-chave, análise de dados secundários e roda de discussão. As equipes possuíam 1637 famílias cadastradas, todas as casas são de tijolo, 80,1\% com tratamento da água em domicílio e 99,6\% com abastecimento pela rede pública. A coleta do lixo é pública, 99,9\% possui rede de esgoto e 99,5\% energia elétrica. A observação ativa indicou predominância de comércio informal. Equipamentos sociais foram identificados, como igrejas, bancos, centro comunitário para prática desportiva, escolas públicas e um Centro de Referência para a Assistência Social, bem como uma universidade pública. As áreas de abrangência apresentam moradores de classe média baixa, com pessoas em situação de pobreza. Os informantes-chave relataram que existem atividades ocupacionais domiciliares frequentes entre as mulheres em idade produtiva. No adoecimento relacionado ao trabalho, o sofrimento mental e a depressão foram apontados como recorrentes, bem como a inexistência de ações intersetoriais. No plano de ação, optou-se pelo problema "Hipertensão Arterial, Diabetes Mellitus e Sofrimentos Mentais como as doenças frequentes entre os usuários trabalhadores". 0 nó-crítico selecionado para a elaboração do plano de ação foi "Organização do processo de trabalho das equipes com fragilidades nas investigações/reconhecimento das condições de saúde do usuário trabalhador". 0 estudo propõe o fortalecimento e a construção de competências que atuem na modificação da realidade social das coletividades, em consonância com o debate atual brasileiro para a proteção e promoção da saúde e para a prevenção de danos à saúde do trabalhador.

Descritores: Saúde do trabalhador; Estratégia Saúde da Família; Planejamento em saúde comunitária; Diagnóstico da situação de saúde.

Study using mixed methods and a constructionist social approach, aiming to analyze the use of Strategic Situational Health Planning to survey the demands related to worker health with two teams of the Family Health Strategy, from May to June 2018. We conducted an active observation of the territory, interviews with key informants, analysis of secondary data, and a group discussion. The teams had 1637 registered families, all the houses are made of brick, $80.1 \%$ have water treatment, and $99.6 \%$ receive their water supply through the public network. Garbage collection is public, $99.9 \%$ houses have a sewage system and $99.5 \%$ electricity. Active observation indicated a predominance of informal commerce. Social facilities were identified, such as churches, banks, community center for sports, public schools and a Reference Center for Social Assistance, as well as a public university. The residents of the areas covered are from the lower middle class, with people in a situation of poverty. Key informants reported that there are frequent household occupational activities among women of productive age. With regards to work-related illness, mental suffering and depression were identified as recurrent, as well as the absence of intersectorial actions. In the plan of action, the problem "Arterial Hypertension, Diabetes Mellitus, and Mental Suffering as frequent diseases among working users" was selected. The major issue selected for the elaboration of the action plan was "Organization of the work process of the teams with weaknesses in the investigations / recognition of the health conditions of the working user". This study seeks to strengthen and build competences that lead to changes in the social reality of collectives, in line with the current Brazilian debate for the protection and promotion of health and for the prevention of damage to the health of workers.

Descriptors: Occupational health; Family Health Strategy; Community health planning; Diagnosis of health situation.

Estudio por métodos mixtos y de abordaje construccionista social, con el objetivo de analizar la conducción del Planeamiento Estratégico Situacional en salud para levantamiento de las demandas relacionadas a la salud del trabajador con dos equipos de la Estrategia Salud de la Familia, realizado de mayo a junio de 2018. Se realizó observación activa del territorio, entrevista con informantes-clave, análisis de datos secundarios y ronda de discusión. Los equipos poseían 1637 familias registradas, todas las casas son de ladrillo, 80,1\% con agua tratada en el domicilio y 99,6\% con abastecimiento por la red pública. La colecta de la basura es pública, 99,9\% posee red de cloaca y 99,5\% energía eléctrica. La observación activa indicó un predominio del comercio informal. Equipamientos sociales fueron identificados, como iglesias, bancos, centro comunitario para práctica deportiva, escuelas públicas y un Centro de Referencia para Asistencia Social, así como una universidad pública. Las áreas de cobertura presentan residentes de clase media baja, con personas en situación de pobreza. Los informantes-clave relataron que existen actividades ocupacionales domiciliarias frecuentes entre las mujeres en edad productiva. En la enfermedad relacionada al trabajo, el sufrimiento mental y la depresión fueron apuntados como recurrentes, así como la inexistencia de acciones intersectoriales. En el plan de acción, se optó por el problema "Hipertensión Arterial, Diabetes Mellitus y Sufrimientos Mentales como las enfermedades frecuentes entre los usuarios trabajadores". El nudo-crítico seleccionado para la elaboración del plan de acción fue "Organización del proceso de trabajo de los equipos con fragilidades en las investigaciones/reconocimiento de las condiciones de salud del usuario trabajador". El estudio propone el fortalecimiento y la construcción de competencias que actúen en la modificación de la realidad social de las colectividades, en consonancia con el debate actual brasilero para la protección y promoción de la salud y para prevenir daños a la salud del trabajador.

Descriptores: Salud laboral. Estrategia de Salud Familiar; Planificación en salud comunitaria; Diagnóstico de la situación de salud.

1. Enfermeira. Doutora em Atenção à Saúde. Epidemiologista Clínica do Hospital de Clínicas da Universidade Federal do Triângulo Mineiro (UFTM). ORCID: 0000-0002-1048-960X E mail: fernandaccamargo@yahoo.com.br

2. Fisioterapeuta. Mestranda do Programa de Pós Graduação em Fisioterapia (PPGF) pela UFTM/Universidade Federal de Uberlândia (UFU), Uberaba, MG, Brasil. ORCID: 0000-0002-4155-8858E-mail: gabi_machado@hotmail.com

3. Fisioterapeuta. Mestranda do PPGF pela UFTM/UFU, Uberaba, MG, Brasil. ORCID: 0000-0003-3892-6936e

E-mail: luanafisioterapiauftm@gmail.com

4. Enfermeira. Fisioterapeuta. Especialista em Saúde da Família. Especialista em Enfermagem do Trabalho. Mestranda do PPGF pela UFTM/UFU, Uberaba, MG, Brasil. ORCID: 0000-0001-9440-3203 E-mail: gabrielasf26@hotmail.com

5. Fisioterapeuta. Mestre em Fisioterapia. Fisioterapeuta da Fisio Prime, Uberaba/MG. ORCID: 0000-0002-6840-1586 E mail: analaura_fisio@hotmail.com 6. Educadora Física. Fisioterapeuta. Mestre em Fisioterapia. Diretora da Clínica de Fisioterapia da Universidade de Uberaba (UNIUBE). ORCID: 0000-0003-2092-3307 E mail: cacosandra1@gmail.com

7. Fisioterapeuta. Doutora em Fisioterapia. Professora Associada do curso de Graduação em Fisioterapia da UFTM e do PPGF da UFTM/UFU Uberaba, MG, Brasil. ORCID: 0000-0002-2317-1326 E-mail: isabelpwalsh@gmail.com 


\section{INTRODUÇÃO}

To Brasil, após 30 anos de Sistema Único de Saúde (SUS), são requeridas estratégias políticas e organizacionais que visem à consolidação e fortalecimento desse sistema ${ }^{1,2}$. 0 exemplo mais recente dessa necessidade reflete-se na $15^{\text {a }}$ Conferência Nacional de Saúde, ocorrida em 2015, cujo lema foi a defesa do cuidado de qualidade como um direito do povo brasileiro mediante valorização do trabalho multiprofissional e interdisciplinar, transformador das práticas de saúde 3 .

Diante do relatório dessa Conferência, foi apresentada a importância de haver, cada vez mais, a manutenção da proteção social universal em saúde ${ }^{3}$. Neste contexto, a expansão da Estratégia de Saúde da Família (ESF) se apresenta como ação prioritária para o fortalecimento do SUS. Associada à expansão, a qualificação do processo de trabalho na ESF também é crucial para que se promova a integralidade das práticas de saúde ${ }^{1,2}$.

A reordenação do funcionamento da rede de serviços de saúde SUS implica em reforçar o papel ordenador da atenção básica por meio da ESF. Enquanto nível de atenção preferencial, deve ser capilar às necessidades ampliadas em saúde e organizadas por práticas que estejam direcionadas ao contexto sócio territorial de indivíduos, famílias e comunidades ${ }^{1,2}$.

Com relação à Saúde do Trabalhador, um grande avanço no Brasil foi seu reconhecimento constitucional como área da saúde pública ${ }^{4}$. No entanto, a redução de vulnerabilidades relativas às condições do ambiente e aos processos de trabalho tem se constituído num importante desafio para o SUS ${ }^{4-6}$.

Tem-se observado, nas ESFs, fragilidades no manejo das questões de saúde do trabalhador, pois não se adota instrumento específico para entender as realidades de trabalho da clientela. Isso acaba dificultando uma possível reflexão das equipes sobre as relações entre trabalho e os processos saúde-doença ${ }^{7}$, embora a Política Nacional de Saúde do Trabalhador e da Trabalhadora do SUS (PNSTT-SUS), ao oferecer as bases conceituais e diretrizes estratégicas para prover a atenção integral aos trabalhadores, reforce, para a sua efetivação, a necessidade do engajamento da atenção básica/ESF ${ }^{4-6}$, propondo que as equipes de atenção básica/ESF estejam capacitadas para o reconhecimento das necessidades da saúde do trabalhador nos territórios e para a vigilância das situações de vulnerabilidade e articulações de ações intersetoriais no enfrentamento dessas demandas ${ }^{4}$.

Dessa maneira, o cuidado à saúde dos trabalhadores na atenção básica/ESF deve considerar uma compreensão ampliada dos processos laborais nos territórios vivos, tendo em vista que o trabalho é um determinante social do processo saúde-doença. É importante que as equipes conheçam os perfis ocupacionais de seu território de responsabilidade, e que o acompanhamento dessa condição esteja incorporado ao cotidiano de prática ${ }^{5,6}$.

Contudo, embora a integração das ações em saúde do trabalhador na atenção básica/ESF seja reconhecida como condição obrigatória para a construção da integralidade do cuidado, grande parte das atividades das equipes ainda se concentra em ações de atendimento pontuais às demandas ${ }^{5,6} \mathrm{e}$ às práticas de intervenção, que se baseiam em análises de situação de saúde da população, planejadas e articuladas sobre os determinantes locais para condições de saúde do usuário trabalhador, e muitas vezes apresentam-se como incipientes 4 .

Na década de 1980, foi apresentado o Planejamento Estratégico Situacional (PES) como proposta teórico-metodológica para planejar e governar, apresentando-se como método facilitador para a geração da viabilidade política dos planos. Nessa concepção, salienta-se que aqueles que planejam devem ser parte da realidade planejada enquanto prática histórica, fato que requer diálogo e interação, pois o diagnóstico da situação permite ter domínio sobre as circunstâncias e não sobre uma verdade objetiva. 0 planejamento concebe que proposições planejadas em saúde levarão à resolução dos problemas de saúde se fundamentadas na interpretação da determinação social do processo de produção desses problemas ${ }^{8,9}$.

Neste âmbito, há preocupações em se inserir, no PES, elementos de um agir comunicativo, como a cooperação, a negociação, a legitimidade, o engajamento participativo dos atores sociais 
e a descentralização. Baseando-se em momentos de discussão aberta, essa forma de pensar o planejamento em saúde torna-se sensível à subjetividade e compreende os contextos sociais não apenas pela abstração estatística. Além disso, o PES como técnica reconhece o tempo como um recurso, assumindo, portanto, a ação de planejar com um caráter ágil e acessível ${ }^{8-10}$.

O PES é estruturado em momentos-chave. No primeiro momento explicativo, realiza-se um diagnóstico situacional, levantando problemas, priorizando e definindo nós críticos. Os nós críticos apoiam a explicação das dificuldades, uma vez que constituem aspectos que interferem na produção de um ou mais problemas ${ }^{9,10}$.

No segundo momento, normativo, define-se objetivos e resultados a serem alcançados, além de estratégias e ações que viabilizem superar os nós-críticos. Nesse momento, observa-se obstáculos e oportunidades internas e externas, bem como o tempo exigido pela resolução dos problemas e as ações necessárias à gestão do plano ${ }^{9,10}$.

No terceiro momento, estratégico, enfatiza-se a importância da análise de recursos econômicos, administrativos e políticos necessários e/ou disponíveis a partir das propostas traçadas. E no último momento, tático operacional, propostas, cronograma, recursos, participantes e responsáveis pelas ações são programados. Discute-se os indicadores de monitoramento do plano e sua avaliação participativa, necessária à promoção das adequações e ajustes dos rumos na sua condução ${ }^{9,10}$.

Neste contexto, considerando o planejamento das ações a partir do território e considerando o diagnóstico de saúde, é possível compreender a situação de saúde segundo outros determinantes, não apenas biológicos ${ }^{5,8}$, levando ao questionamento: Como empreender o PES em saúde para abordar as demandas da saúde do trabalhador na atenção básica/ESF? Assim sendo, este estudo tem como objetivo analisar a condução do Planejamento Estratégico Situacional em saúde para levantamento das demandas relacionadas à saúde do trabalhador com equipes da Estratégia Saúde da Família.

\section{MÉTODO}

Trata-se de um estudo por métodos mistos. Esse tipo de estudo promove entendimento sobre um fenômeno por uma vinculação entre pesquisa quantitativa e qualitativa, considerando que a compreensão do fenômeno não pode ser alcançada somente por uma destas abordagens. A confiabilidade dos métodos mistos orienta-se pela organização de suas etapas, pela combinação entre os tipos de pesquisa e pelo arcabouço teórico orientador (teorização) ${ }^{11,12}$.

Vale destacar que, como etapa crucial de pesquisas que envolvem métodos mistos, apresenta-se a necessidade de integração dos resultados para subsidiar as respostas das questões de estudo. Outro aspecto importante é a necessidade de expressar as etapas da pesquisa por meio de uma matriz de implementação ${ }^{11,13}$. Conforme representado pela Figura 1, foi adotada como estratégia para a condução a perspectiva transformativa sequencial dos métodos mistos ${ }^{11}$.

Figura 1 - Diagrama da estruturação do percurso metodológico da pesquisa conforme a perspectiva de métodos mistos (matriz de implementação). Uberaba, Minas Gerais, 2018.

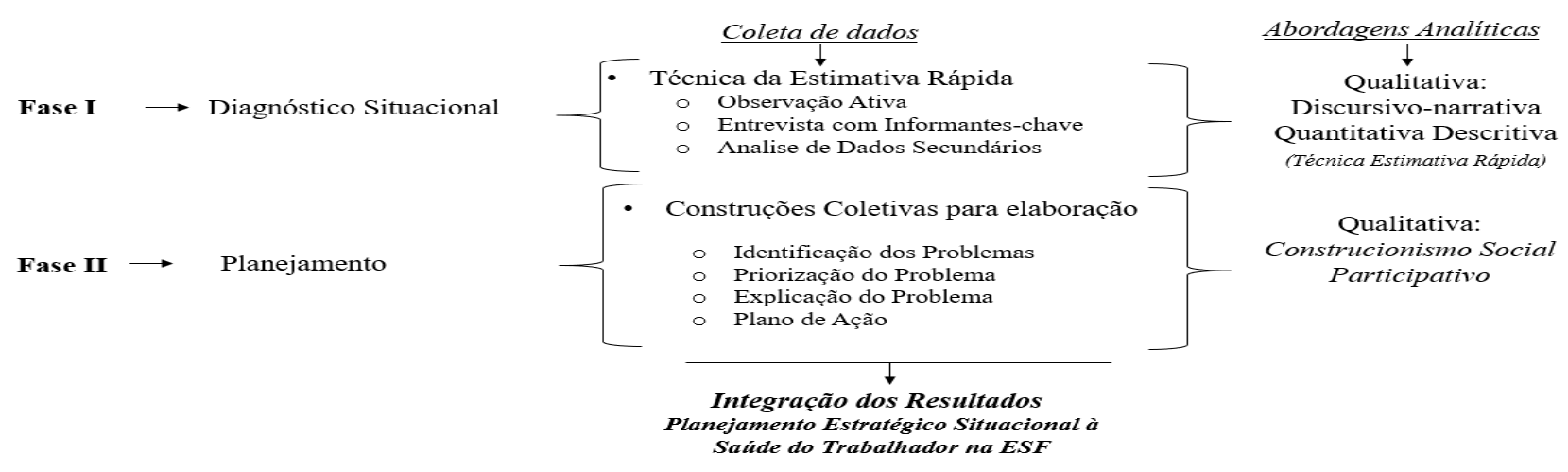


O arcabouço teórico-metodológico (teorização) se pautou no construcionismo social, o qual busca compreender a maneira pela qual as pessoas geram significados a respeito de si mesmas e do mundo, construindo conhecimento conjuntamente aos atores envolvidos, de forma participativa ${ }^{14}$.

A coleta de dados ocorreu entre os meses de maio e junho de 2018. A Fase I foi desenvolvida junto a duas equipes de ESF que habitualmente exercem suas atividades em formato de integração ensino-serviço, pois são assistidas por um centro de saúde escola conveniado à Universidade Federal do Triângulo Mineiro (UFTM). Foi uma escolha intencional, representada pelo vínculo prévio entre serviço e universidade, que, por conseguinte, torna-o espaço viável para a articulação pretendida pelo estudo.

Para a Fase I, a coleta de dados foi organizada pela técnica da estimativa rápida ${ }^{14}$, a saber: observação ativa, entrevistas com informantes-chave e análise de dados secundários, sendo a coleta orientada por roteiros elaborados pelos autores. Na observação ativa das áreas de abrangência das duas equipes de ESF, foram considerados o tipo de atividade produtiva predominante, os recursos sociocomunitários e as áreas de maior vulnerabilidade.

Inicialmente, foram contatadas as enfermeiras responsáveis pelas duas equipes para apresentação da proposta e para que as mesmas convidassem todos os profissionais. Participaram, efetivamente, nove agentes comunitários de saúde (ACS), de ambas as equipes, que se fizeram presentes no momento da educação permanente e foram considerados informantes-chave por serem moradores da comunidade, imersos no cotidiano vivo das condições que permeiam o território. Foram excluídos aqueles em férias ou afastamento no momento da coleta.

A coleta, junto às ACS, foi organizada no local. Foi orientada por entrevista semiestruturada contendo questões sobre as ocupações/profissões mais frequentes entre os moradores da área, se os trabalhos são formais ou informais, qual o perfil de adoecimento mais frequente dos trabalhadores na área, e que tipo de trabalho/trabalhadores mais adoecem. A aplicação do instrumento teve duração de 20 minutos.

Em seguida, foi realizada uma roda de discussão junto aos ACS para ampliação das informações quanto às ações de saúde: se usualmente fazem perguntas sobre a atividade laboral do usuário durante os atendimentos, se percebem articulação junto ao Centro de Referência de Saúde do Trabalhador (CEREST) da localidade, se tem sido preenchida a notificação compulsória para agravos ocupacionais. A roda de conversas teve duração de 90 minutos.

Quanto à análise de dados secundários, foram obtidos registros dos sistemas de informação das equipes para a caracterização sociodemográfica e ocupacional da população adscrita. Foram acessados dados disponibilizados pelas equipes (relatório do sistema e-SUS para o ano de 2017), complementados por dados da área de abrangência disponibilizados pelo CEREST através do relatório sobre o perfil produtivo realizado em 2015.

A Fase II foi desenvolvida em sala apropriada na universidade durante os encontros da disciplina de pós-graduação. Foi realizada a análise do diagnóstico situacional (Fase I) por meio de uma roda de discussão entre os pesquisadores.

Ainda em consonância com a estruturação processual para o PES, houve um diálogo para o levantamento dos problemas, priorizados segundo critérios de governabilidade da equipe das ESF em enfrentá-los (denotados valores de 0 a 10, sendo o maior valor a maior governabilidade), de motivação/importância para propor ações (Fora/Pouco; Parcial; Dentro/Alta) e relacionados à urgência de seu impacto na comunidade (classificada como baixa/intermediária/alta) ${ }^{13}$.

Na sequência, o problema selecionado foi descrito e explicado por análise de nós-críticos. Foi elaborado um plano de intervenções por construções coletivas e participativas entre os pesquisadores durante a roda de discussão, resultando em um quadro de ações para o enfrentamento do nó-crítico prioritário. Foram identificados os recursos críticos para implantação da proposta, sendo eles político (correspondente à negociação com instâncias ou 
setores), administrativo (recursos financeiros, pessoal ou material) e cognitivo (necessidade de ampliação da expertise da equipe para o manejo) ${ }^{13}$.

Quanto às análises empreendidas para a Fase I, dados numéricos foram apresentados por estatística descritiva, registros da observação ativa de forma narrativo-discursiva, fragmentos dos discursos de ACS foram utilizados, e, para a preservação do sigilo e anonimato, codificados por numeral (ACSn).

Para a Fase II, todo o conteúdo discutido foi registrado em caderno de campo para posterior organização das informações, transcrição para o estudo, integração dos resultados, análise e condução do PES.

Sobre os aspectos éticos, a pesquisa foi aprovada pelo Comitê de Ética em Pesquisa da UFTM em 2017, sob o parecer $\mathrm{n}^{\circ} 2.427 .323$. A coleta de dados foi realizada após a assinatura do Termo de Consentimento Livre Esclarecido pelos participantes.

\section{RESULTADOS}

Quanto ao diagnóstico situacional da saúde do trabalhador no território da ESF, a observação ativa indicou predominância de comércio informal, sendo os estabelecimentos de diferentes tipos, envolvendo mercado de alimentos (mercadinhos), lojas de artefatos diversos, como papelarias, e lojas de pequeno porte que vendem roupas, com farmácias e consultórios odontológicos nas proximidades. Ainda distribuídos no interior das áreas, há garagens e funilarias de carros, comércio noturno com pontos de prostituição, além de bares em pontos diversos do bairro.

Equipamentos sociais foram identificados, como igrejas, bancos, centro comunitário para prática desportiva e escolas públicas. Há, ainda, um Centro de Referência para a Assistência Social (CRAS) na região. A própria universidade constitui-se como um equipamento social da área adjacente.

De forma geral, as áreas de abrangência apresentam características de territórios com moradores de classe média baixa e setores mais focados no território, com pessoas em situação de pobreza. A conformação das áreas de abrangência permite que microáreas estejam mais afastadas dos recursos sociais, imprimindo maiores vulnerabilidades a essa população mais periférica.

Os nove informantes-chave participantes relataram que as ocupações laborais recorrentes na área de abrangência são de pequenos comerciantes, domésticas e trabalhadores da construção civil, como pedreiros e serventes de pedreiro, sendo que os dois últimos desempenham suas atividades laborais fora do bairro.

Existem atividades ocupacionais domiciliares frequentes entre as mulheres em idade produtiva. São mulheres que fazem marmitas ou outros alimentos, doceiras e salgadeiras, vendedoras de cosméticos no próprio domicílio, além daquelas que exercem atividades de manicure e cabeleireira nos quintais de suas casas.

Mencionaram que, durante a noite, existem pontos de aglomeração de jovens e adultos ingerindo bebidas alcoólicas, como bares, oportunizando algum contato entre parceiros, existindo, também, situações de prostituição em locais específicos durante a noite.

A questão do tráfico de drogas na região foi alertada pelos informantes, que relataram a existência de pré-adolescentes e adolescentes envolvidos na venda. Nos discursos, mencionaram áreas no território delimitadas para o "comércio" das drogas.

Há, conforme relato, imposições da criminalidade, com recorrência de furtos aos indivíduos e ao comércio local, o que acaba por influenciar na ausência de circulação livre nas praças e demais lugares do território, especialmente no horário noturno.

Sobre o adoecimento relacionado ao trabalho entre a população da área de abrangência, informantes-chave manifestaram sofrimento mental e depressão como recorrentes na população da área adscrita: 
[...]Cansaço mental, a gente vê muito trabalhador reclamando disso (ACS 1 ).

Os trabalhadores buscam o serviço para tratar de hipertensão e diabetes, percebendo que essas doenças se ampliaram entre a população adulta trabalhadora. Contudo, ao discutir a situação da saúde do trabalhador da área de abrangência, acabavam por discutir, também, as precariedades que envolviam a sua própria condição de saúde e trabalho. [...] Eu mesma afastei com diagnóstico de depressão por quatro meses que foi indeferido pelo INSS, fiquei esse tempo sem receber. Aqui não pode adoecer $\left(A C S_{2}\right)$.

Não foram apontadas, pelos informantes-chave, ações intersetoriais articuladas junto às equipes de ESF para a promoção da saúde do trabalhador, nem a organização de redes locais de proteção. Não foi mencionada a articulação de representantes para a participação nos processos decisórios e avaliativos do centro de saúde escola, como a composição do conselho local de saúde. Ainda sobre a organização do serviço de saúde para atender às necessidades do usuáriotrabalhador, identificaram fragilidades na sua operacionalização no cotidiano das atividades de ambas as equipes:

[...] Aplicação das políticas de saúde, muitas não acontecem $\left(\right.$ ACS $\left._{3}\right)$.

0 profissional do sexo não foi compreendido, no discurso dos informantes-chave, como uma categoria que necessita de cuidados específicos, como uma negligência velada ao acolhimento das demandas desse usuário trabalhador.

Relataram, ainda, não ter, na rotina cotidiana, a prática de preencherem as notificações de agravos relacionados ao trabalho. Debateram que na unidade não há um fluxo ou atividade específica para abordar as questões do usuário trabalhador, como, por exemplo, um terceiro turno de atendimento, e que existem interações junto ao CEREST regional, mas, frequentemente, essas interações são informativas-normativas. Não conseguiram identificar encontros para problematização do contexto ou planejamento de ações conjuntas.

Sobre a análise dos dados secundários, de acordo com os dados do e-SUS, as equipes possuem 1637 famílias cadastradas $\left(\mathrm{ESF}_{1}=800 ; \mathrm{ESF}_{2}=837\right)$. Quanto à estrutura física das áreas, $80,1 \%$ das casas possui tratamento da água em domicílio. 0 abastecimento de água é realizado pela rede pública em 99,6\% das casas. Todas as casas são de tijolo e 99,5\% possui energia elétrica. 0 destino do lixo é realizado pela coleta pública e $99,9 \%$ das casas possui rede de esgoto.

As atividades mais comuns foram: cabeleireiro, cozinheira, manicure, doméstica, pedreiro e vendedor, atividades que, de forma geral, exigem menor grau de escolaridade ou especialização para seu desempenho.

Tabela 1. Caracterização da população da área de abrangência das equipes de ESF quanto ao perfil produtivo. Uberaba, Minas Gerais, 2018.

\begin{tabular}{lrr}
\multicolumn{1}{c}{ Aspectos do Perfil Produtivo } & \multicolumn{2}{c}{ Equipes } \\
\cline { 2 - 3 } & ESF1 (n) & ESF2(n) \\
\hline Famílias que participaram do Perfil Produtivo & & 837 \\
\hline Famílias cadastradas na ESF & 800 & 837 \\
Famílias entrevistadas & 629 & 2915 \\
\hline Pessoas que participaram do Perfil Produtivo & & 2310 \\
\hline Pessoas participantes & 2911 & 47 \\
Participantes em idade ativa & 2371 & 51 \\
Participantes que relataram trabalho informal & & \\
\hline
\end{tabular}

Fonte: Uberaba, Secretaria Municipal de Saúde, CEREST, Perfil Produtivo, 2015.

Conforme a análise do diagnóstico situacional, as construções coletivas para o PES em saúde do trabalhador no território das ESF possibilitaram o delineamento de cinco macroproblemas relacionados ao contexto socioterritorial de estudo (Quadro 1). 
Quadro 1. Identificação e priorização dos problemas relacionados à saúde do trabalhador na população da área de abrangência das equipes de ESF, conforme diagnóstico situacional. Uberaba, Minas Gerais, 2018.

\begin{tabular}{|c|c|c|c|}
\hline Problemas Identificados & Governabilidade & Urgência & Motivação \\
\hline $\begin{array}{l}\text { Rede local intersetorial com vínculos inexistentes ou frágeis } \\
\text { para a promoção de ações para a Saúde do Trabalhador. }\end{array}$ & 5 & Média & Parcial \\
\hline $\begin{array}{l}\text { Atividades produtivas, conforme perfil, relacionadas a } \\
\text { ocupações com baixa escolaridade, resultando em } \\
\text { subempregos. }\end{array}$ & 1 & Baixa & $\begin{array}{l}\text { Fora/ } \\
\text { Pouca }\end{array}$ \\
\hline $\begin{array}{l}\text { Tráfico de drogas sendo uma fonte de renda para pré- } \\
\text { adolescentes e adolescentes. }\end{array}$ & 4 & Alta & Parcial \\
\hline $\begin{array}{l}\text { Hipertensão Arterial, Diabetes Mellitus e Sofrimentos } \\
\text { Mentais como as doenças frequentes entre os usuários } \\
\text { trabalhadores. }\end{array}$ & 7 & Alta & $\begin{array}{l}\text { Dentro/ } \\
\text { Elevada }\end{array}$ \\
\hline $\begin{array}{l}\text { Organização do processo de trabalho das equipes ESF com } \\
\text { fragilidades nas investigações/reconhecimento das } \\
\text { condições de saúde do usuário trabalhador. }\end{array}$ & 8 & Intermediária & $\begin{array}{l}\text { Dentro/ } \\
\text { Elevada }\end{array}$ \\
\hline
\end{tabular}

Foi priorizado, para a elaboração do plano de ação, o problema "Hipertensão Arterial, Diabetes Mellitus e Sofrimentos Mentais como as doenças frequentes entre os usuários trabalhadores". Esse problema se explica, pelo relato dos informantes-chave, como sendo um agravo recorrente entre usuários trabalhadores assistidos pelas ESF, por ser uma realidade em relação à qual o grupo de pesquisadores apresentava maior governabilidade e motivação para intervenção.

Dessa maneira, o nó-crítico selecionado para a elaboração do plano de ação foi "Organização do processo de trabalho das equipes ESF com fragilidades nas investigações/reconhecimento das condições de saúde do usuário trabalhador". Sobre o plano de ação, foram definidas iniciativas passíveis de serem implementadas no cenário de estudo (Quadro 2).

Quadro 2. Plano de ação para enfrentamento dos problemas relacionados à saúde do trabalhador na população da área de abrangência das equipes ESF, conforme diagnóstico situacional. Uberaba, Minas Gerais, 2018.

\begin{tabular}{|c|c|}
\hline Organização do processo de trabalho das equipe & $I S$ \\
\hline Ações & Recurso Crítico \\
\hline $\begin{array}{l}\text { Compartilhar o diagnóstico situacional com as equipes ESF } \\
\text { para discussões e construções coletivas quanto ao plano de } \\
\text { ação. }\end{array}$ & $\begin{array}{l}\text { - Político: Autorização das chefias para } \\
\text { realização do encontro. }\end{array}$ \\
\hline $\begin{array}{l}\text { Sensibilizar toda equipe de ESF quanto à importância da } \\
\text { Notificação Compulsória de Agravos Relacionados ao } \\
\text { Trabalho. }\end{array}$ & $\begin{array}{l}\text { - Político: Autorização das chefias para } \\
\text { realização do encontro. } \\
\text { - Cognitivo: organização da sensibilização. }\end{array}$ \\
\hline $\begin{array}{l}\text { Desenvolver material informativo sobre ações dos } \\
\text { equipamentos sociais da área de abrangência, incluindo a } \\
\text { universidade, quanto à disponibilização de iniciativas para } \\
\text { qualificação profissional e para "cuidado à saúde do } \\
\text { trabalhador". }\end{array}$ & $\begin{array}{l}\text { - Cognitivo: elaboração do material informativo. } \\
-\quad \text { Administrativo: identificação dos } \\
\text { equipamentos sociais locais e dos recursos que } \\
\text { disponibilizam (mapeamento). }\end{array}$ \\
\hline $\begin{array}{l}\text { Realizar atividade junto aos informantes-chave (ACS) sobre } \\
\text { práticas para o cuidado à saúde e para o manejo das questões } \\
\text { cotidianas relacionadas a seu trabalho. }\end{array}$ & $\begin{array}{l}\text { - Político: Autorização das chefias para a } \\
\text { realização do encontro. } \\
\text { - Cognitivo: organização da sensibilização. }\end{array}$ \\
\hline
\end{tabular}

\section{DISCUSSÃO}

Para estruturação das práticas no contexto da ESF é prioritário reconhecer o território como um espaço social onde a sociedade se constrói e se reconstrói de acordo com o cerne de seu processo de trabalho e produção, dividindo-se em classes diferenciadas, resultando em desigualdade de acesso aos serviços de saúde e aos bens de consumo ${ }^{15-17}$. 
A vulnerabilidade social é compreendida como a sobreposição de riscos sociais e ambientais que se concentram em determinadas áreas e ampliam as situações de pobreza e demais mazelas. A realidade discutida no presente estudo coincide com realidades existentes em muitas áreas periféricas e periurbanas brasileiras ${ }^{15,16}$.

Evidencia-se que, desde sua implantação, a ESF teve como prerrogativa iniciar a cobertura assistencial pelas áreas de maior vulnerabilidade social, imprimindo, na interatuação entre equipes ESF e nas relações comunitárias, necessidades de preparo para enfrentamento de adversidades do contexto territorial, como violência e outras vulnerabilidades expressas pela desigualdade social ${ }^{15-17}$.

Existem lacunas importantes para o agir das equipes quanto às circunstâncias acerca do PES e voltadas à saúde do trabalhador na atenção básica/ESF. De forma geral, não se tem considerado o diagnóstico situacional em saúde do trabalhador para planejar as ações ${ }^{18}$. As ações da PNSTT-SUS desenvolvidas pelos CEREST, de forma espontânea ou normativa, não têm sido suficientes para que haja integração entre estes serviços e as equipes de atenção básica/ESF 19 .

É limitante a incorporação da saúde do trabalhador na atenção básica/ESF sem que sejam considerados os próprios trabalhadores de saúde e sua atividade profissional. Podem ser observadas, nessa dimensão, fragilidades quanto à formação desses, além da ausência do apoio institucional no estabelecimento de linhas de cuidados nessa temática. Dificuldades estruturais são persistentes na atenção básica/ESF, destacando precariedades da rede física e de informatização18,19.

0 estabelecimento da relação entre o trabalho e as queixas/adoecimento apresentados pelo usuário-trabalhador possibilitam desvelar a contribuição do trabalho no processo saúdedoença e orientar as condutas a serem tomadas ${ }^{20,21 .}$

Destaca-se a relevância de se reconhecer o usuário trabalhador e estabelecer a relação entre o trabalho e a condição de saúde-doença, uma vez que, na atual conjuntura socioeconômica brasileira, há um contingente da população trabalhadora que se encontra no setor informal e/ou precarizado de trabalho, ou está desempregada e em situação de vulnerabilidade social, em muitos casos desenvolvendo atividades produtivas no domicílio e no peridomicílio ${ }^{20,21}$.

A PNSTT-SUS destaca a importância da análise da situação de saúde dos trabalhadores no contexto territorial, especialmente para orientar a identificação dos usuários e dos grupos mais vulneráveis, como, por exemplo, os desempregados e aqueles inseridos em atividades produtivas domiciliares e/ou em relações informais e precárias de trabalho, ou expostos a atividades perigosas para a saúde ${ }^{20}$.

Cabe aos CEREST um papel importante enquanto apoiadores das ações, atuando como referências no processo de trabalho das equipes da atenção básica/ESF, buscando identificar estratégias oportunas para que características e organizações das práticas de saúde das equipes da atenção básica/ESF favoreçam o acesso dos trabalhadores e trabalhadoras ao cuidado da saúde, com qualidade e resolutividade, sendo potencialmente capazes de apreender os mecanismos pelos quais o trabalho influencia suas condições de vida e saúde ${ }^{20,21}$.

Quanto à rede de nós-críticos, foram priorizadas as interferências diretas relativas ao processo de trabalho das equipes ESF, o qual se distancia das necessidades da população trabalhadora. Ao mesmo tempo, essa organização do processo de trabalho encontra-se limitada na articulação intersetorial da rede local, que poderia promover proteção ampliada aos usuários trabalhadores, inclusive frente à possibilidade de se viabilizar, pelo trabalho em rede, oportunidades para qualificação técnica e aumento da escolaridade da população de usuários trabalhadores, possibilitando sua busca por melhor inserção no mercado de trabalho.

A organização, o modo e o processo de trabalho das equipes ESF não estimulam a aproximação às necessidades dos usuários trabalhadores, dificultando o engajamento social e a atuação democrático-participativa junto ao serviço de saúde. A não mobilização social dos 
usuários trabalhadores limita o enfrentamento de questões como a criminalidade e o tráfico de drogas, mantendo o cotidiano vivencial dessa população sob essa realidade de violências.

A validação e o compartilhamento do diagnóstico situacional junto às equipes ESF apresentam-se como iniciativa crucial, sendo o resultado apresentado no presente estudo como uma primeira perspectiva a ser induzida no território. Respeitar o referencial do PES de dialogia e engajamento junto aos atores sociais envolvidos no cenário a ser planejado é crucial para a criação da viabilidade política para implantação do plano ${ }^{22-24}$.

É preciso levar em conta que um ator social com conhecimento do problema e capacidade de raciocínio estratégico com certeza enfrentará melhor um problema do que alguém com baixo conhecimento da realidade e apenas conhecimento metodológico ${ }^{22-26}$.

Sobretudo após o diagnóstico situacional em saúde foi possível identificar a necessidade de ações voltadas para especificidades da vida cotidiana nas comunidades, imprimindo ao planejamento iniciativas singulares aos contextos sociais e mediante o interesse dos atores engajados 23,24 .

Considerar o território como base operacional para o planejamento das ações e incorporar os problemas advindos das relações da produção e do trabalho em uma atuação integrada na atenção básica/ESF têm sido discutidas como iniciativas de maior viabilidade para que, com isso, sejam organizadas ações estratégicas que contribuam na materialização da promoção da saúde do trabalhador, conforme apontam relatos de experiência ${ }^{23-25}$.

Embora existam problemas identificados pela análise situacional, há, no território de estudo, outros recursos, como a existência de aparelhos sociais que podem contribuir na perspectiva da promoção da saúde do trabalhador. Nesse sentido, a universidade pública federal, um dos equipamentos sociais do território, tem como parte de sua missão apoiar a implementação de iniciativas, pela integração do ensino-serviço, que favoreçam o cuidado integral e a vigilância à saúde do trabalhador nos territórios.

Iniciativas de PES como estratégia para integração ensino-serviço na ESF têm sido reproduzidas em cenários de formação com o intuito de incentivar os alunos a discutir as problemáticas de saúde pública, acrescidas de aulas práticas para reconhecimento de diferentes cenários para análise de situações de saúde $22,23,26$.

\section{CONCLUSÃO}

O presente estudo analisou o empreendimento do PES em saúde, orientado pelas fases de diagnóstico da situação de saúde e das construções coletivas para planejamento. Além disso, viabilizou a aproximação da realidade dos usuários trabalhadores, permeada por empregos informais que requerem baixa escolaridade, sendo seus domicílios espaços de atividades produtivas. Acresce-se a isso o comércio de drogas, a prostituição e as imposições da criminalidade, de modo que essa realidade se assemelha à de muitas áreas periféricas brasileiras.

Sobre o planejamento em si, revelou-se como nó crítico a organização do processo de trabalho das equipes ESF abordadas. Esse processo apresenta fragilidades para a investigação das condições de saúde do usuário trabalhador.

Considera-se que a implementação de ações intersetoriais de engajamento social para a mobilização participativa e de vigilância das condições de saúde do usuário trabalhador estão vinculadas ao enfrentamento do nó crítico relatado.

0 planejamento foi desenvolvido como atividade de integração ensino-serviço. Por conseguinte, apresenta-se a necessidade de compartilhar o diagnóstico situacional com as equipes ESF, além da necessidade de avaliação, em pesquisas posteriores, o impacto das ações planejadas sobre as equipes e sobre a comunidade.

Limitações deste estudo revelam-se na impossibilidade de generalizações, mediante as especificidades do território de análise. Contudo, foi possível a compreensão de práticas de 
saúde voltadas para o usuário trabalhador no contexto da ESF e da necessidade de se ressignificar ações de promoção e vigilância da saúde do trabalhador na comunidade.

Reconhece-se a lacuna produzida pela não descrição da percepção de outros informanteschave sobre o território. Entretanto, os aspectos concernentes ao trabalho de ACS, por estarem imersos no cotidiano vivo dos territórios e até mesmo por serem moradores deste, legitima a participação deles como atores oportunos.

O fato de as construções coletivas terem se desenvolvido apenas no cenário de formação pode ser um outro limitante, o que deverá ser trabalhado em estudos posteriores quando ocorrer o compartilhamento dos resultados junto às equipes de ESF. Conforme consta no plano, deverá ser articulada a ampliação da discussão com os demais atores sociais do território estudado.

0 potencial de contribuição do estudo apresenta-se quanto ao incentivo para que atividades semelhantes possam ser reproduzidas na formação em saúde, a fim de se fortalecer a construção de competências que atuem na modificação da realidade social das coletividades, em consonância com o debate atual brasileiro sobre a necessidade de defesa e fortalecimento da missão do SUS de proteger e promover a saúde e prevenir os danos à saúde do trabalhador.

\section{REFERÊNCIAS}

1. Santos DS, Mishima SM, Merhy EE. Processo de trabalho na Estratégia de Saúde da Família: potencialidades da subjetividade do cuidado para reconfiguração do modelo de atenção. Ciênc Saúde Colet. [Internet]. 2018 [citado em 05 fev 2020]; 23(3):861-80. Disponível em: http://www.scielo.br/pdf/csc/v23n3/1413-8123-csc-23-03-0861.pdf. DOI: 10.1590/141381232018233.03102016

2. Campos GWS. SUS: o que e como fazer? Ciênc Saúde Colet. [Internet]. 2018 [citado em 05 fev 2020]; 23(6):1707-14. Disponível em: http://www.scielo.br/pdf/csc/v23n6/1413-8123-csc23-06-1707.pdf. DOI: 10.1590/1413-81232018236.05582018

3. Conselho Nacional de Saúde (Brasil). Documento orientador de apoio aos debates da 15a Conferência Nacional de Saúde [Internet]. Brasília, DF; maio 2015 [citado em 11 jun 2018]. Disponível em: http:// conselho.saude.gov.br/web_15cns/docs/05mai15_Documento_Orientador_15CNS.pdf

4. Gomez CM, Vasconcellos LCF, Machado JMH. Saúde do trabalhador: aspectos históricos, avanços e desafios no Sistema Único de Saúde. Ciênc Saúde Colet. [Internet]. 2018 [citado em 05 fev 2020]; 23(6):1963-70. Disponível em: http://www.scielo.br/pdf/csc/v23n6/14138123-csc-23-06-1963.pdf. DOI: 10.1590/1413-81232018236.04922018

5. Silva TL, Dias EC, Pessoa VM, Fernandes LMM, Gomes EM. Saúde do trabalhador na Atenção Primária: percepções e práticas de equipes de Saúde da Família. Interface (Botucatu) [Internet]. 2014 [citado em 05 fev 2020]; 18(49):273-88. Disponível em: http://www.scielo.br/pdf/icse/v18n49/1807-5762-icse-1807-576220130227.pdf. $\quad$ DOI: 10.1590/1807-57622013.0227

6. Machado JMH, Santana VS, Campos A, Ferrite S, Peres MC, Galdino A, et al. Situação da Rede Nacional de Atenção Integral em Saúde do Trabalhador (RENAST) no Brasil, 2008-2009. Rev Bras Saúde Ocup. [Internet]. 2013 [citado em 05 fev 2020]; 38(128):243-56. Disponível em: http://www.scielo.br/pdf/rbso/v38n128/12.pdf

7. Lacaz FAC, Trapé A, Soares CB, Santos APL. Estratégia Saúde da Família e Saúde do Trabalhador: um diálogo possível?. Interface (Botucatu) [Internet]. 2013 [citado em 05 fev 2020]; 17(44): 75-87. Disponível em: http://www.scielo.br/pdf/icse/v17n44/a07v17n44.pdf 8. Uribe Rivera FJ, Artmann E. Planejamento e gestão em saúde: histórico e tendências com base numa visão comunicativa. Ciênc Saúde Colet. [Internet]. 2010 [citado em 05 fev 2020]; 15(5):2265-74. Disponível em: http://www.scielo.br/pdf/csc/v15n5/v15n5a02.pdf 
9. Kleba ME, Krauser IM, Vendruscolo C. O planejamento estratégico situacional no ensino da gestão em saúde da família. Texto \& Contexto Enferm. [Internet]. 2011 [citado em 05 fev 2020]; 20(1):184-93. Disponível em: http://www.scielo.br/pdf/tce/v20n1/22.pdf

10. Silva AK, Sousa JP, Rodrigues W, Cançado AC. Planejamento Estratégico Situacional - PES: uma análise bibliométrica da produção científica brasileira. Rev Serv Público. [Internet]. 2017 [citado em 05 fev 2020]; 68(2):365-88. Disponível em: https://revista.enap.gov.br/index.php/RSP/article/view/1269

11. Lorenzini E. Pesquisa de métodos mistos nas ciências da saúde. Rev Cuid. [Internet]. 2017 [citado em 05 fev 2020]; 8(2):1549-60. Disponível em: http://www.revenf.bvs.br/pdf/cuid/v8n2/2346-3414-cuid-8-2-1549.pdf. DOI: http://dx.doi.org/10.15649/cuidarte.v8i2.406

12. Creswell JW. A concise introduction to mixed methods research. Thousand Oaks: Sage; 2015. 13. Campos FCC, Faria HP, Santos MA. Planejamento e avaliação das ações de saúde. 2ed. Belo Horizonte: NESCON/UFMG; 2010. (Caderno de Estudos do Curso de Especialização em Atenção Básica em Saúde da Família)

14. Souza LV. Recursos dialógicos e seu uso em sala de aula no ensino superior: contribuições construcionistas sociais. Rev Grad USP [Internet]. 2018 [citado em 05 fev 2020]; 3(1):97-100. Disponível em: content/uploads/2018/06/Gradmais6_R04_LauraVilela.pdf. 376X.v3i1p97-100

15. Oliveira LP, Camargo FC, Hemiko IH. Violência relacionada ao trabalho das equipes de saúde da família. Rev Enferm Atenção Saúde [Internet]. 2013 [citado em 05 fev 2020]; 2(2 esp):46-56. Disponível em: http://seer.uftm.edu.br/revistaeletronica/index.php/enfer/article/view/388. DOI: https://doi.org/10.18554/

16. Pinto AGA, Jorge MSB, Marinho MNASB, Vidal ECF, Aquino OS, Vidal ECF. Experiences in the Family Health Strategy: demands and vulnerabilities in the territory. Rev Bras Enferm. [Internet]. 2017 [citado em 05 fev 2020]; 70(5):920-7. Disponível em: http://www.scielo.br/pdf/reben/v70n5/0034-7167-reben-70-05-0920.pdf

17. Dias MSA, Parente JRF, Vasconcelos MIO, Dias FAC. Intersetorialidade e Estratégia Saúde da Família: tudo ou quase nada a ver? Ciênc Saúde Colet. [Internet]. 2014 [citado em 05 fev 2020]; 19(11):4371-82. Disponível em: http://www.scielo.br/pdf/csc/v19n11/1413-8123-csc-1911-4371.pdf. DOI: 10.1590/1413-812320141911.11442014

18. Bastos-Ramos TP, Santana VS, Ferrite S. Estratégia Saúde da Família e notificações de acidentes de trabalho, Brasil, 2007-2011. Epidemiol Serv Saúde [Internet]. 2015 [citado em 05 fev 2020]; 24(4):641-50. Disponível em: http://www.scielo.br/pdf/ress/v24n4/2237-9622ress-24-04-00641.pdf. DOI: 10.5123/S1679-49742015000400006

19. Dias MDA, Bertolini GCS, Pimenta AL. Saúde do trabalhador na atenção básica: análise a partir de uma experiência municipal. Trab Educ Saúde [Internet]. 2011 [citado em 05 fev 2020]; 9(1):137-48. Disponível em: http://www.scielo.br/pdf/tes/v9n1/v9n1a10.pdf

20. Amorim LA, Silva TL, Faria HP, Machado JMH, Dias EC. Vigilância em saúde do trabalhador na atenção básica: aprendizagens com as equipes de saúde da família de João Pessoa, Paraíba, Brasil. Ciênc Saúde Colet. [Internet]. 2017 [citado em 05 fev 2020]; 22(10):3403-13. Disponível em: http://www.scielo.br/pdf/csc/v22n10/1413-8123-csc-22-10-3403.pdf. DOI: 10.1590/1413-812320172210.17532017

21. Silva RF, Fonseca BMC. A vigilância nos ambientes e processos de trabalho em Palmas Tocantins: diagnóstico situacional e contribuições ao setor. Tempus. [Internet]. 2018 [citado em 05 fev 2020]; 11(2):199-217. Disponível http://www.tempusactas.unb.br/index.php/tempus/article/view/2236. DOI: http://dx.doi.org/10.18569/tempus.v11i2.2236

22. Gentilini JA. Atores, cenários e planos: o planejamento estratégico situacional e a educação. Cad Pesqui. [Internet]. 2014 [citado em 05 fev 2020]; 44(153):580-601. Disponível em: 
http://www.scielo.br/pdf/cp/v44n153/a06v44n153.pdf.

DOI: http://dx.doi.org/10.1590/198053142954

23. Silva REBG, Ramalho APQ, Souza CCO. Oficinas de planejamento em saúde na disciplina de Saúde Coletiva: relato de experiência. Rev Grad USP [Internet]. 2018 [citado em 05 fev 2020]; 3(2):87-91. Disponível em: https://www.revistas.usp.br/gradmais/article/view/147907. DOI: https://doi.org/10.11606/issn.2525-376X.v3i2p87-91

24. Silva CSSL, Koopmans FF, Daher DV. O Diagnóstico Situacional como ferramenta para o planejamento de ações na Atenção Primária a Saúde. Rev Pró-Universus . 2016; [citado em 05 fev 2020] 7(2):30-3. Disponível em: http://editora.universidadedevassouras.edu.br/index.php/RPU/article/view/345

25. Silva A, Ferraz L, Rodrigues-Junior SA. Ações em saúde do trabalhador desenvolvidas na atenção primária no município de Chapecó, Santa Catarina. Rev Bras Saúde Ocup. [Internet]. 2016 [citado em 05 fev 2020]; 41:e16. Disponível em: http://www.scielo.br/pdf/rbso/v41/2317-6369-rbso-41-e16.pdf. DOI: http://dx.doi.org/10.1590/2317-6369000122415

26. Souza KMJ, Seixas CT, David HMSL, Costa AQ. Contribuições da saúde coletiva para o trabalho de enfermeiros. Rev Bras Enferm. [Internet]. 2017 [citado em 05 fev 2020]; 70(3):5439. Disponível em: http://www.scielo.br/pdf/reben/v70n3/pt_0034-7167-reben-70-030543.pdf. http://dx.doi.org/10.1590/0034-7167-2016-0401

\section{CONTRIBUIÇÕES}

Fernanda Carolina Camargo e Isabel Aparecida Porcatti de Walsh contribuíram na concepção, delineamento, análise e interpretação dos dados, redação e revisão. Gabriela Gonçalves Machado, Luana Rodrigues Rosseto Felipe, Gabriela Souza Faria, Ana Laura Nogueira e Sandra Cristina Romano Marquez Reis participaram na concepção, obtenção dos dados, delineamento, análise e interpretação dos dados, redação e revisão.

\section{Como citar este artigo (Vancouver)}

Camargo FC, Machado GG, Felipe LRR, Faria GS, Nogueira AL, Reis SCRM, et al. Planejamento estratégico situacional em saúde: abordagem da saúde do trabalhador na Estratégia Saúde da Família. REFACS [Internet]. 2020 [citado em inserir dia, mês e ano de acesso]; 8(2): 249260. Disponível em: inserir link de acesso. DOI: inserir link do DOI.

\section{Como citar este artigo (ABNT)}

CAMARGO, F. C.; MACHADO, G. G.; FELIPE, L. R. R.; FARIA, G. S.; NOGUEIRA, A. L.; REIS, S.C.R.M. et al. Planejamento estratégico situacional em saúde: abordagem da saúde do trabalhador na Estratégia Saúde da Família. REFACS, Uberaba, MG, v. 8, n. 2, p. 249-260, 2020. Disponível em: inserir link de acesso. Acesso em: inserir dia, mês e ano de acesso. DOI: inserir link do DOI.

\section{Como citar este artigo (APA)}

Camargo, F.C., Machado, G.G., Felipe, L.R.R., Faria, G.S., Nogueira, A.L., ... Walsh, I.A.P. (2020). Planejamento estratégico situacional em saúde: abordagem da saúde do trabalhador na Estratégia Saúde da Família. REFACS, 8(2), 249-260. Recuperado em: inserir dia, mês e ano de acesso de inserir link de acesso. DOI: inserir link do DOI. 